Research Article

Wenbin $\mathrm{Xu}^{\star}$, Yingying Yang, Chenwei Dai, and Jingang Xie

\title{
Optimization of spinning parameters of 20/316L bimetal composite tube based on orthogonal test
}

https://doi.org/10.1515/secm-2020-0026

Received Jul 18, 2019; accepted Dec 02, 2019

\begin{abstract}
The spin forming parameters of bimetallic composite pipe were optimized b y FEM and experiment, and the torque and the residual contact pressure were analyzed during forming process. Adoption of The orthogonal test of four factors and five levels to gain the optimal spinning parameters $\left(\delta=0.16 \mathrm{~mm}, \psi=0.4 \mathrm{~mm}, \beta=3.0^{\circ}, \mathrm{f}=\right.$ 0.5 ) and the effects of factors on analysis indicators under the condition of maximum residual contact pressure and small torque. The simulation results showed that the residual contact pressure was nearly $1 \mathrm{MPa}$ higher and the torque was lower about $160 \mathrm{~N} \cdot \mathrm{m}$ than unoptimized results. It proved that the orthogonal test method was effective for the optimization of spinning parameters of bimetal composite tube. The accuracy of numerical simulation value was verified by the drawing experiment of the composite tube.
\end{abstract}

Keywords: Bimetal composite tube, Spin forming, Residual contact pressure

\section{Introduction}

Bimetal composite tube uses carbon steel tube as the base to ensure its excellent comprehensive mechanical properties, and according to the requirement with special performance material as the liner to meet the special requirements [1-4]. Bimetal composite tubes fully use the base and liner in the best physical and chemical properties. It has high strength but also excellent corrosion resistance, high-temperature resistance, low-temperature resistance, wear-resistance and other special performance [5-7]. As

\footnotetext{
*Corresponding Author: Wenbin Xu: Anhui Vocational And Technical College, Hefei, Anhui, 230011, China;

Email: xuwenbin1987@hotmail.com

Yingying Yang: Urban construction college of AHJZU, Hefei, Anhui, 230011, China

Chenwei Dai, Jingang Xie: Anhui Vocational And Technical College, Hefei, Anhui, 230011, China
}

Ә Open Access. ( 2020 W. Xu et al., published by De Gruyter. License a result, bimetal composite tube can be widely used in petroleum, chemical and other fields.

The forming technology of metal composite pipe mainly includes hydroforming, drawing forming and explosion forming. Due to the dual effects of physical nonlinearity and geometric nonlinearity, it is difficult to study on the theoretical of the bimetal composite tube [8]. With the development of computer technology, the finite element numerical simulation method has been widely used in metal plastic forming. X.F.Lu and X. Zheng simulated the drawing forming process of bimetal-lined pipe made of 20 carbon steel as the base tube and 316L stainless steel as the liner tube by means of the finite element analysis software ABAQUS, optimized the drawing process parameters of bimetal composite tube, and obtained the optimal drawing process parameters at the maximum residual contact pressure [9]. Drawing forming of composite pipe also has been reported in other literatures [10, 11]. They analyzed the stress distribution in the drawing process of the composite pipe and studied the influence of drawing parameters on the bonding strength of the composite pipe by orthogonal test and got a modified approach for drawing force estimation of bi-metallic composite pipe forming in the light of the results of FEM simulation. Z.Y. Bi and C.Wang analyzed the minimum expansion pressure and the relationship between the expansion pressure and residual contact stress for the L360QS/Incoloy825 nickel base alloy hydraulic expansion pipe. They pointed out that the minimum expansion pressure and the residual contact pressure $\mathrm{Pc}^{\star}$ can be obtained by using ABAQUS finite element method and verified by hydraulic bulge test [12]. Other authors also investigated the hydroforming of composite tube by experimental or finite element [13-16]. They studied the influence factors of hydraulic formation failure of composite pipe by experiment, and examined the interaction of material properties and die geometry on the selection of hydroforming process parameters and discussed the effects of the strain-hardening exponent, initial tube wall thickness, and die corner radii on corner filling and thickness distribution of the hydroformed tube. B. Cao and Z.S.Zhang introduced ANSYS finite element software to analyze the composite dynamic process, and obtained the 
displacement of key nodes of the liner and the stress distribution of the composite tube after forming [17]. Yu yong et al.applied PVDF piezoelectric thin film sensor to measure the dynamic parameters of the explosive welding and studied the impact pressure of the aluminum layer on the steel layer in the aluminum-steel underwater explosive [18]. The explosive forming of metal composite tubes also has been reported in other literatures [19-21]. They studied the effect of the explosive mass reduction on the bonding interface of the pipes and resolved the backward method of charge and low energy efficiency of explosives by using honeycomb structure explosives and double sided explosive cladding. T. Nechaykina et al. showed the viability of manufacturing of multi-layer steel/vanadium alloy/steel composite tubes by numerical simulations and experiment, studied the interface bonding of vanadium alloy and stainless steel by using scanning electron microscopy and microhardness measurements, and obtained the process conditions suitable for producing a good quality product [22]. Pawel Kazanowski et al. investigated the influence of the initial billet geometry on the product geometry during bi-material rod extrusion, optimized initial inner material length within a bi-material billet and noted the complex interface structure between AA2014 and AA6063 by light optical microscopy [23]. However, if the composite tube formed by drawing encounters high temperature, it would tend to be stratified, and the tube would fail due to the release of residual contact pressure. The forming force of hydroforming is uniform and can be calculated, but the device is pretty complicated and high requirements for the sealing of the device. The composite tube forming by $\mathrm{Ex}$ plosive is difficult to accurately determine the amount of explosive, the interface junction between base tube and liner is easy to form waveform and scrap, and special production site is needed and the production process has certain risks. The spinning forming equipment is simple, and the forming quality of the composite tube is relatively good. However, few literatures reported the FEM for the spinning process of composite tubes and optimized its forming parameters. This research mainly aimed at establishing the numerical simulation model of bimetal composite tube formed by spinning, analyzing the equivalent plastic strain, applying the orthogonal experiment design method and range difference to get the significant parameter of bimetal composite tube, and using experiments to verify the accuracy of the simulation.

\section{Finite element analysis of spinning forming of compound tube}

\subsection{Build finite element model}

The size of the carbon steel base tube is $\Phi 89 \times 4.5 \mathrm{~mm}$ and 316L liner size is $\Phi 79.2 \times 1 \mathrm{~mm}$. The gap between base and liner tube $\psi$ is $0.4 \mathrm{~mm}$. The embedding quantity $\delta$ is 0.14 $\mathrm{mm}$, orientation Angle $\beta$ (the centerline of the roller and liner axis Angle) is $2.5^{\circ}$, the feed rate $f$ (axial feed roller speed/angular velocity) is 0.3 . The three-dimensional simulation model of the bimetallic clad pipe is shown as the Figure 1.

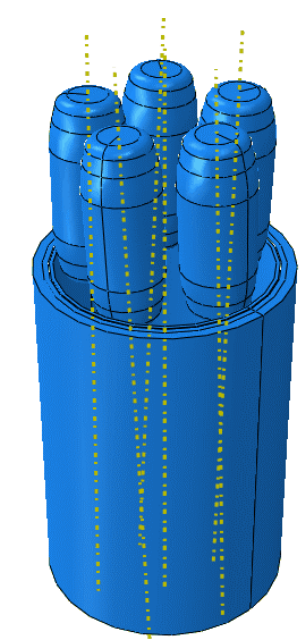

Figure 1: 3D model of bimetallic clad pipe formed by spinning

\subsection{Defining the load and boundary conditions}

In the spinning process of the composite tube, the liner should be flanged and fixed on the base tube. Therefore, the displacement/Angle constraint mode is adopted when defining boundary conditions. $\mathrm{U} 2=0$ is defined at the end of the liner and base tube. The axial loading speed defined as $\mathrm{v} 2=18.84 \mathrm{~mm} / \mathrm{s}$, the rotating speed $\mathrm{n}=600 \mathrm{r} / \mathrm{min}$ and the amplitude curve of smooth step is introduced for loading. 


\subsection{Contact mode and mesh division}

Applying the method of surface to surface contact between the outer wall of the liner and the inner wall of the base tube and assuming the inner wall of the base tube as the main contact surface and the outer wall of the liner as the slave contact surface simulated the forming process. The surface to surface contact method was also adopted between the roller and the inner wall of the liner inner wall, and the roller as the main contact surface and the inner wall of the liner as the slave contact surface. The finite slip was introduced in each contact pair and the motion contact as the mechanical constraint. The C3D8R hexahedron unit was employed to mesh the liner and base tube, the liner was divided into 94000 hexahedron units and 79000 hexahedron units for the base tube was divided. Because of the shear load, the grid distortion may occur in the liner and base tube and it seriously affects the analytical accuracy, misconvergence and even interrupts the program. The usage of the ALE adaptive grid control prevents the occurrence of this phenomenon.

\section{Simulation results}

\subsection{Equivalent plastic strain analyses}

The equivalent plastic strain (PEEQ) of the base tube and liner in the stable spinning stage of the composite tube was shown in Figure 2:

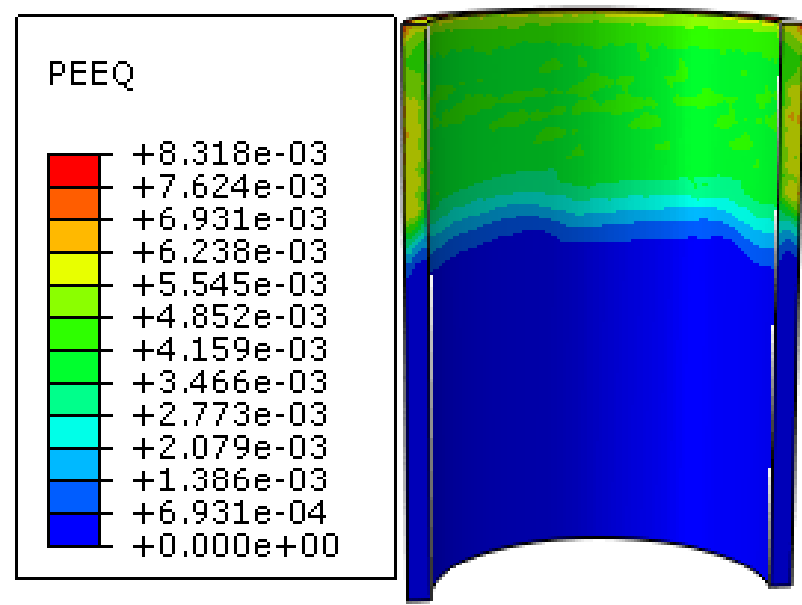

(a) base tube
The material hardening model was used to calculate the accumulated plastic strain, and the PEEQ can be used to express the accumulated plastic strain. According to the shear failure criterion, the material failure may happen when the PEEQ reached above 1.0. Figure 2 (a) showed that the equivalent plastic strain of the base tube was almost close to zero. It can be considered that the base tube was always within the elastic range during the forming process, the theoretical calculation with multiple tube spinning forming and the actual production safety requirements were consistent. The liner would be plastic deformation because of its large deformation. As it can be seen from Figure 2 (b) of the equivalent plastic strain distribution of the liner, plastic deformation occurred in the liner, and the maximum PEEQ was 0.2279, which didn't exceed 1.0 , so the material didn't fail due to large deformation.

\subsection{Residual contact pressure and torque}

Residual contact pressure is the main index for the quality of composite tube. Under the condition of the base tube being in plastic deformation and the liner being well, the greater the residual contact pressure between the liner and the base tube, the better the quality of the composite tube. Figure 3 showed the distribution of the average residual contact pressure obtained along the uniformly selected path along the inner wall of the base tube. It can be seen that the residual contact pressure of each path was inconsistent, and the average residual contact pressure of each path was 8.20MPa. Metal accumulation formed by uneven metal-flowing in the forming process would lead to uneven
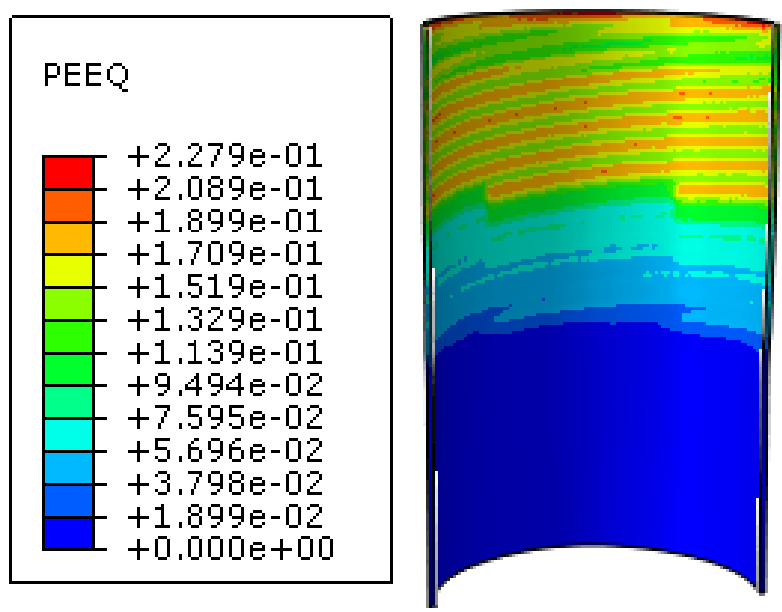

(b) liner

Figure 2: Plastic strain of base tube and lined tube 


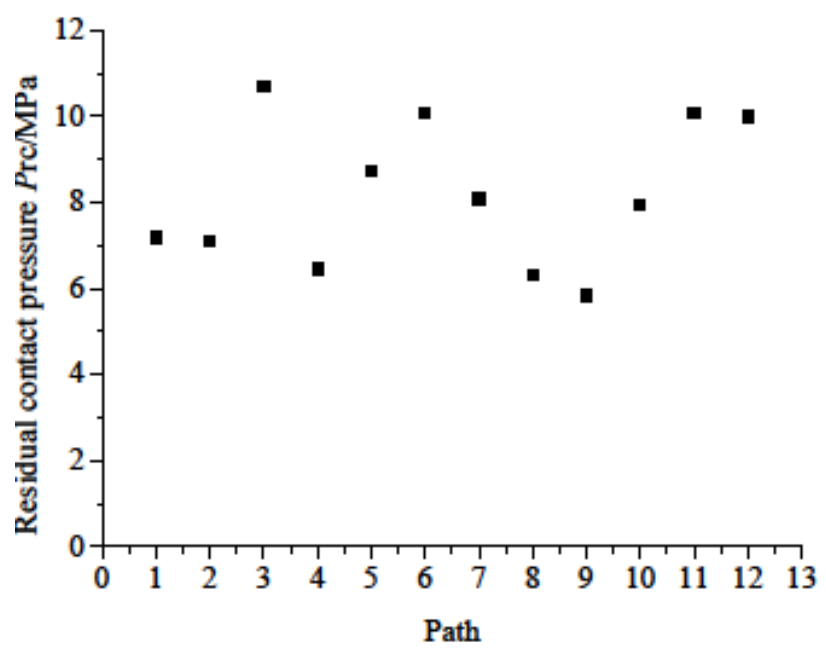

Figure 3: Residual contact pressure between lined tube and base tube

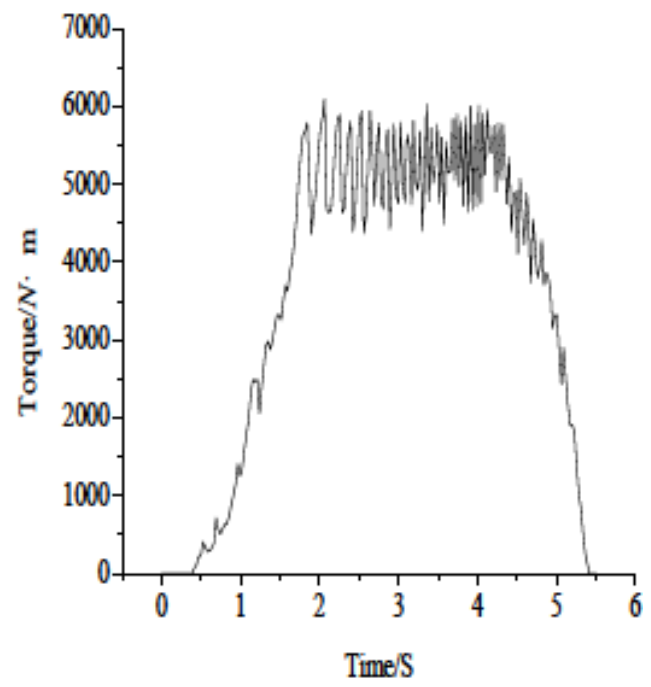

Figure 4: Torque

residual contact pressure. In practical production, physical defects, such as small concave anti-bulge on inner wall of base tube or outer wall of liner, would also lead to uneven distribution of contact pressure between liner and base tube.

The torque distribution of the composite tube in spinning process was shown in Figure 4. The forming process went through three stages: in the initial spinning stage, the spinning mold came into contacting with the liner, the metal-flowing started to increase, the contact pressure also increased gradually, and the torque increased with time. In the stable spinning stage, the roller was in full contact with the liner, and the metal-flowing and contact pressure tended to be stable, so the torque fluctuated in a small range and tended to be stable. Spinning unloading stage, spinning roller and liner separated gradually, contact pressure reduced and torque also reduced to zero. The average torque of the entire spinning process was $3943.69 \mathrm{~N} \cdot \mathrm{m}$.

\section{Orthogonal experimental analysis of compound tube spinning forming}

In order to get high bonding strength (residual contact pressure) and low required torque and reduce the number of numerical simulation as much as possible, the following four factors were selected: A-embedding amount $\delta$, B-liner and base tube gap $\psi$, C-guiding Angle $\beta$, D-feed rate $f$, and 5 levels for each factor. The orthogonal table selected according to the horizontal number was L25 (56), and the orthogonal test scheme and orthogonal test factor level developed were shown in the table below. Finite element analysis software ABAQUS was used to conduct numerical simulation on the spinning process parameters of 25 groups in Table 1.

\subsection{Range analysis}

The range analysis method can estimate the influence of various factors on the test results. The larger the range $R$ value is, the greater the influence of the corresponding factors will be. Therefore, the influence of each factor on the test evaluation index can be ensured by the size of the range $\mathrm{R}$ value, and the better level of each factor can be ensured according to the size of the $k$ value, so as to determine the optimal level combination.

From Table 3, The range analysis of the four factors on the residual contact pressure was $R A>R C>R D>R B$, which meant that the embedding amount exerted the greatest influence on the residual contact pressure, followed by the leading Angle, the feed rate, and the liner and base tube clearance, respectively. The four factors of A, B, C and D respectively gained the maximum residual contact pressure at the level of A4, B3, C5 and D5, so the corresponding optimal spinning process parameter was A4B3C5D5.

It can be seen from table 4 that the range analysis of torque by the four factors was $\mathrm{RA}>\mathrm{RC}>\mathrm{RB}>\mathrm{RD}$. It was also basically consistent with the range analysis results of residual contact pressure. The embedding amount and steering Angle had a large influence on the residual contact pressure and torque, and the gap between liner and base tube and the feed rate $f$ had a low influence on them. The min- 
Table 1: Scheme of orthogonal experiment

\begin{tabular}{ccccccc}
\hline Test number & $\mathrm{A}$ & $\mathrm{B}$ & $\mathrm{C}$ & $\mathrm{D}$ & $P_{r c} / \mathrm{MPa}$ & Torque/N·m \\
\hline 1 & 0.10 & 0.30 & $3.0^{\circ}$ & 0.3 & 2.93 & 3219.61 \\
2 & 0.10 & 0.35 & $3.5^{\circ}$ & 0.35 & 3.16 & 3419.32 \\
3 & 0.10 & 0.40 & $4.0^{\circ}$ & 0.4 & 4.56 & 3559.63 \\
4 & 0.10 & 0.45 & $4.5^{\circ}$ & 0.45 & 4.74 & 3681.15 \\
5 & 0.10 & 0.50 & $5.0^{\circ}$ & 0.5 & 5.20 & 3873.26 \\
6 & 0.12 & 0.30 & $3.5^{\circ}$ & 0.4 & 5.63 & 3546.46 \\
7 & 0.12 & 0.35 & $4.0^{\circ}$ & 0.45 & 6.53 & 3637.29 \\
8 & 0.12 & 0.40 & $4.5^{\circ}$ & 0.5 & 7.42 & 3773.03 \\
9 & 0.12 & 0.45 & $5.0^{\circ}$ & 0.3 & 7.09 & 4186.13 \\
10 & 0.12 & 0.50 & $3.0^{\circ}$ & 0.35 & 4.83 & 3548.25 \\
11 & 0.14 & 0.30 & $4.0^{\circ}$ & 0.5 & 8.33 & 3748.13 \\
12 & 0.14 & 0.35 & $4.5^{\circ}$ & 0.3 & 7.20 & 4105.91 \\
13 & 0.14 & 0.40 & $5.0^{\circ}$ & 0.35 & 8.20 & 4305.54 \\
14 & 0.14 & 0.45 & $3.0^{\circ}$ & 0.4 & 6.26 & 3715.14 \\
15 & 0.14 & 0.50 & $3.5^{\circ}$ & 0.45 & 7.39 & 3845.23 \\
16 & 0.16 & 0.30 & $4.5^{\circ}$ & 0.35 & 8.74 & 4173.54 \\
17 & 0.16 & 0.35 & $5.0^{\circ}$ & 0.4 & 9.13 & 4354.74 \\
18 & 0.16 & 0.40 & $3.0^{\circ}$ & 0.45 & 8.08 & 3860.67 \\
19 & 0.16 & 0.45 & $3.5^{\circ}$ & 0.5 & 8.47 & 4001.76 \\
20 & 0.16 & 0.50 & $4.0^{\circ}$ & 0.3 & 9.11 & 4267.37 \\
21 & 0.18 & 0.30 & $5.0^{\circ}$ & 0.45 & 9.27 & 4457.39 \\
22 & 0.18 & 0.35 & $3.0^{\circ}$ & 0.5 & 8.44 & 3939.09 \\
23 & 0.18 & 0.40 & $3.5^{\circ}$ & 0.3 & 7.73 & 4253.25 \\
24 & 0.18 & 0.45 & $4.0^{\circ}$ & 0.35 & 7.83 & 4373.62 \\
25 & 0.18 & 0.50 & $4.5^{\circ}$ & 0.4 & 7.51 & 4445.12 \\
\hline
\end{tabular}

Table 2: Factors and levels of orthogonal experiment

\begin{tabular}{|c|c|c|c|c|c|}
\hline level & 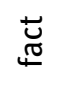 & $\begin{array}{c}\mathrm{A} \\
\delta /(\mathrm{mm})\end{array}$ & $\begin{array}{c}\text { B } \\
\psi /(\mathrm{mm})\end{array}$ & $\begin{array}{c}\mathrm{C} \\
\beta\left({ }^{\circ}\right)\end{array}$ & $\begin{array}{l}\mathrm{D} \\
f\end{array}$ \\
\hline level 1 & & 0.10 & 0.30 & 3.0 & 0.3 \\
\hline level 2 & & 0.12 & 0.35 & 3.5 & 0.35 \\
\hline level 3 & & 0.14 & 0.40 & 4.0 & 0.4 \\
\hline level 4 & & 0.16 & 0.45 & 4.5 & 0.45 \\
\hline level 5 & & 0.18 & 0.50 & 5.0 & 0.5 \\
\hline
\end{tabular}

imum torque was obtained at the level of A1, B1, C1 and D5, so the optimal process parameter should be A1B1C1D5. Overall consideration of torque and the <CJ/T 192-2004 lined stainless-steel tube $>$ standard for the requirement of the residual contact pressure, the optimal parameter combination was acquired at A4B3C1D5.
Table 3: Residual contact pressure of orthogonal results

\begin{tabular}{ccccc}
\hline \multicolumn{5}{c}{ Residual contact pressure $P_{r c} / \mathrm{MPa}$} \\
\hline $\mathrm{k}_{n}$ & $\mathrm{~A}$ & $\mathrm{~B}$ & $\mathrm{C}$ & $\mathrm{D}$ \\
$\mathrm{k}_{1}$ & 4.12 & 6.98 & 6.11 & 6.81 \\
$\mathrm{k}_{2}$ & 6.30 & 6.89 & 6.48 & 6.55 \\
$\mathrm{k}_{3}$ & 7.48 & 7.20 & 7.27 & 6.62 \\
$\mathrm{k}_{4}$ & 8.71 & 6.88 & 7.12 & 7.20 \\
$\mathrm{k}_{5}$ & 8.16 & 6.81 & 7.78 & 7.57 \\
$\mathrm{R}$ & 4.59 & 0.39 & 1.67 & 1.02 \\
Optimal & $\mathrm{A} 4$ & $\mathrm{~B} 3$ & $\mathrm{C} 5$ & $\mathrm{D} 5$ \\
\hline
\end{tabular}

\subsection{Comparison of optimized and unoptimized results}

The optimized parameters were used for numerical simulation and compared with unoptimized results. The differences between them were shown in Figure 5 and Figure 6 . 


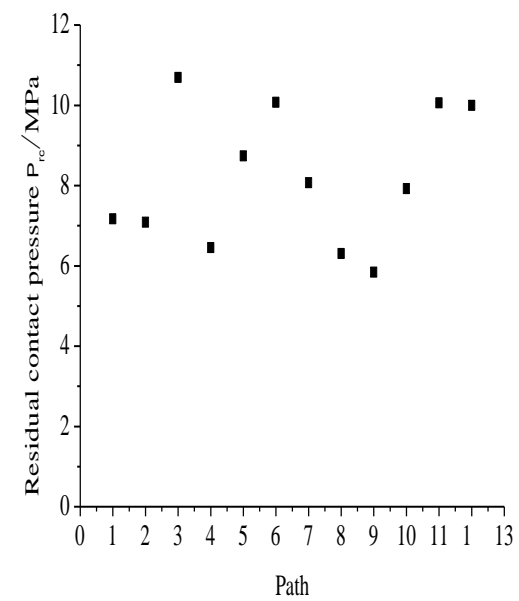

(a)

Figure 5: Residual contact pressure

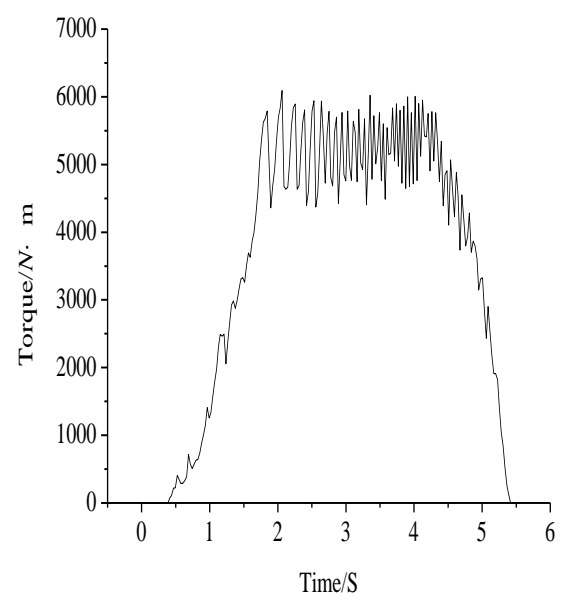

(a)

Figure 6: Torque

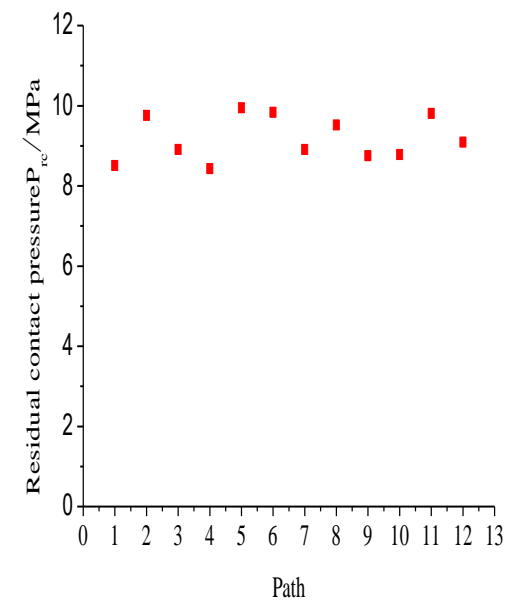

(b)

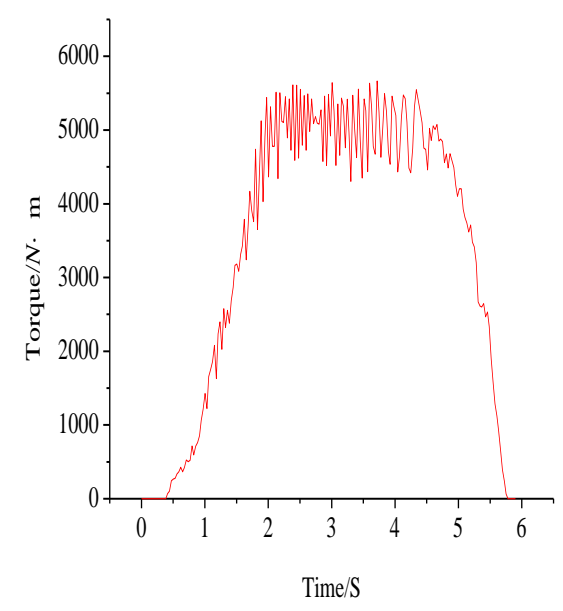

(b)

\begin{tabular}{ccccc}
\hline $\begin{array}{c}\text { Torque } \\
/ \mathrm{N} \cdot \mathrm{m}\end{array}$ & & & & \\
\hline $\mathrm{k}_{n}$ & $\mathrm{~A}$ & $\mathrm{~B}$ & $\mathrm{C}$ & $\mathrm{D}$ \\
$\mathrm{k}_{1}$ & 3550.59 & 3829.03 & 3656.55 & 4006.45 \\
$\mathrm{k}_{2}$ & 3738.23 & 3850.42 & 3813.20 & 3964.05 \\
$\mathrm{k}_{3}$ & 3943.99 & 3891.27 & 3917.21 & 3924.22 \\
$\mathrm{k}_{4}$ & 4131.62 & 3991.56 & 4035.75 & 3896.35 \\
$\mathrm{k}_{5}$ & 4293.69 & 3995.85 & 4235.41 & 3867.05 \\
$\mathrm{R}$ & 743.1 & 145.43 & 5788.86 & 139.4 \\
Optimal & $\mathrm{A} 1$ & $\mathrm{~B} 1$ & $\mathrm{C} 1$ & $\mathrm{D} 5$ \\
\hline
\end{tabular}

From Figure 5 (b), it can be seen that the range of residual contact pressure was form $8.4 \mathrm{MPa}$ to $10 \mathrm{MPa}$, which was smaller than unoptimized results and the quality of the tube was more stable. The average residual contact pressure was 9.19 MPa, nearly $1 \mathrm{MPa}$ higher than unoptimized results. From the Figure 6 (b), the average torque was $3783.61 \mathrm{~N} \cdot \mathrm{m}, 160 \mathrm{~N} \cdot \mathrm{m}$ less than unoptimized results.

\section{Experimental analyses}

The preparation of the test in accordance with Table 5 and composite tube samples were made to verify the reliability of the simulation. In the middle of the samples, the base 

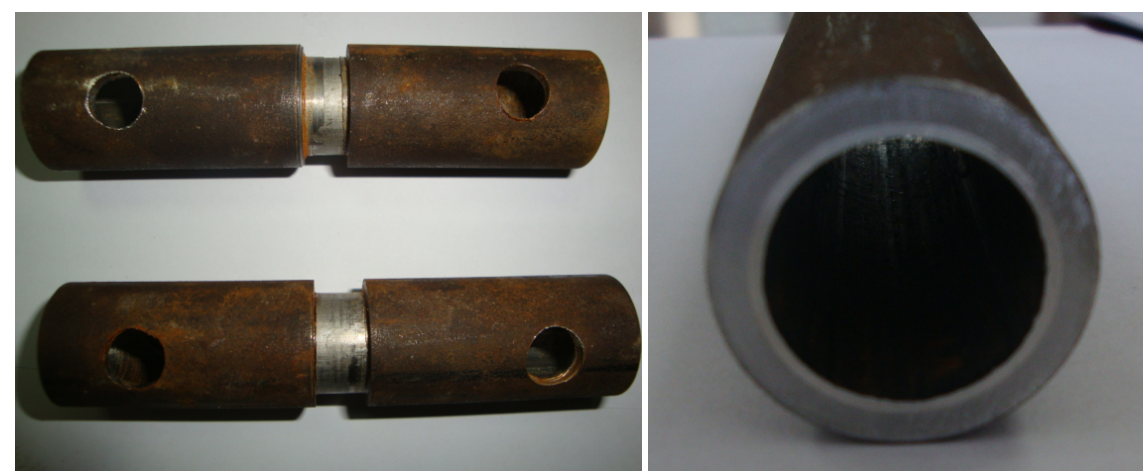

Figure 7: The entity graph of bimetallic clad tube specimen

tube carbon steel tube cut off $10 \mathrm{~mm}$, and the complete lined stainless-steel tube was left. The two $\Phi 20 \mathrm{~mm}$ holes were drilled at both ends of specimens to conveniently clamp for pull-out test. The resulting entity diagram was shown in Figure 7.

\subsection{Pull-out test}

The holes on both ends of the specimen were clamped by the jacket on the material testing machine. One end was fixed and the other end could be moving. The testing machine applied tension to the removable jacket and pulled it out according to the standard of $<\mathrm{CJ} / \mathrm{T}$ 192-2004 lined stainless-steel tube>. The force corresponding to the displacement of the liner and the base tube under the action of tension was the binding force $\mathrm{F}$ at the interface of the liner and the base tube separation, from the formula $\mathrm{P}_{r c}=$ $\mathrm{F} / \pi \mu \mathrm{D}_{i} \mathrm{H}$, where $\mathrm{D}_{i}$ : inner diameter of the liner base tube of the composite tube. H: effective binding length of composite tube sample. Friction coefficient of liner and base tube, $\mu=0.21$.

\subsection{Experimental scheme}

According to the influence factor of residual contact pressure and the limitation of test conditions, four groups of tests were conducted, as shown in Table 5. The test param-

Table 5: Spinning test

\begin{tabular}{ccccc}
\hline Pilot program & $\delta$ & $\psi$ & $\beta$ & $f$ \\
\hline 1 & 0.10 & 0.35 & 3.5 & 0.35 \\
2 & 0.14 & 0.45 & 3.0 & 0.40 \\
3 (Optimization) & 0.16 & 0.40 & 3.0 & 0.50 \\
4 & 0.18 & 0.50 & 4.5 & 0.40 \\
\hline
\end{tabular}

eters in the test table were selected according to the orthogonal test and test conditions.

\subsection{Experimental results}

From Figure 8, the residual contact pressure by simulating was not much different from the experimental value, with the mutual error of about $15 \%$, under the acceptable range of engineering, because the simulated value was obtained under the assumption of the liner and base tube being ideal, and it would cause the simulated value larger than the test value. Moreover, the concave resistance, bending, uneven wall thickness and poor cleaning of liner and base tube during the actual forming of composite tube would reduce the residual contact stress.

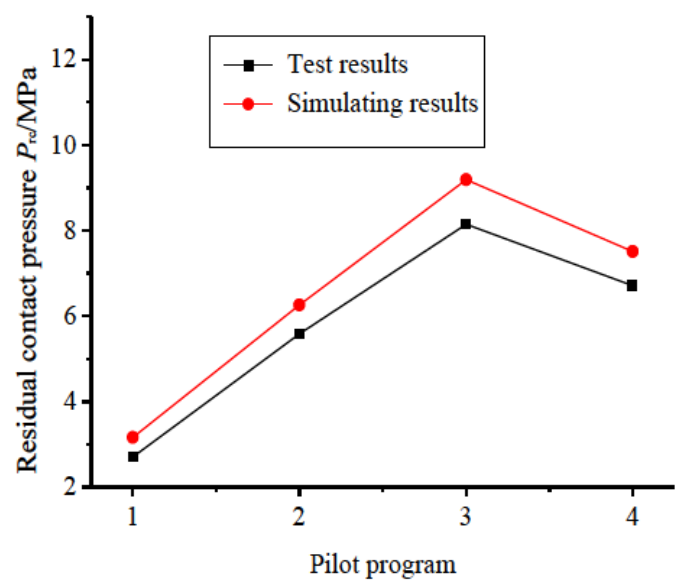

Figure 8: The comparison of residual contact pressure 


\section{Conclusions}

Through numerical simulation and experimental study on spinning forming of bimetallic composite pipe, the following conclusions are obtained:

1. The numerical simulation model of bimetal composite tube formed by spinning was established. Experimental value and simulation value were compared and it proved the feasibility of the numerical simulation method for spinning forming of the metal composite tube.

2. The residual contact pressure and the equivalent plastic strain of liner and base tube and the required torque were obtained. It provided the technical basis for the practical production of the composite tube.

3. The influence of the embedding amount on the residual contact pressure was the largest, followed by the guiding angle, the feeding rate $f$ and the liner and base tube clearance.

4. The optimal spinning forming technology parameters ( $\left.\delta=0.16 \mathrm{~mm}, \psi=0.4 \mathrm{~mm}, \beta=3.0^{\circ}, f=0.5\right)$, the residual contact pressure nearly $1 \mathrm{MPa}$ higher and the required torque reduced $160 \mathrm{~N}^{\star} \mathrm{m}$ than that unoptimized results.

Acknowledgement: This work was supported by the Fundamental Research Funds for Anhui vocational and technical college, Anhui Provincial Natural Science Foundation (No. KJ2018B0003).

\section{References}

[1] Scott DA, Wolgemuth GA, Aikin JA. Hydraulically expanded tubeto-tube sheet joints. J Press Vessel Technol. 1984;106(1):104-9.

[2] Berski S, Dyja H, Maranda A, Nowaczewski J, Banaszek G. Analysis of quality of bimetallic rod after extrusion process. J Mater Process Technol. 2006;177(1-3):582-6.

[3] Guo X, Tao J, Wang W, Li H, Wang C. Effects of the inner mould material on the aluminium-316 L stainless steel explosive clad tube. Mater Des. 2013;49:116-22.

[4] Krishnamurthy R. Hot Metal Gas Forming of Magnesium Tubes. Compos. Part. International Conference on Physical\&Numerical Simulation of Materials Processing, 2004,34(2): 15-17.

[5] Khosravifard A, Ebrahimi R. Investigation of parameters affecting interface strength in $\mathrm{Al} / \mathrm{Cu}$ clad bimetal rod extrusion process. Mater Des. 2010;31(1):493-9.
[6] Alcaraz JL, Gil-Sevillano J. An analysis of the extrusion of bimetallic tubes by numerical simulation. J.Mech.Sci. 2016;38(2):15773.

[7] MahjabinTaskin, GinshiroUtsumi, YoshimineKato. Observation of ultrasonic signal and measure-ment of $\mathrm{H}_{2}$ concentration from the exterior of a metal pipe. J Hydrogen Energy. 2019, 44(41): 03-12.

[8] Krajewski PE, Morales AT. Tribological Issues During Quick Plastic Forming. J Mater Eng Perform. 2004;13(6):701-6.

[9] Lu XF, Zheng X. Optimization of drawing parameters for 20/316L bimetal-lined tube based on FEM simulation. J Chinese Journal of Nonferrous Metals. 2011;21(1):205-13.

[10] Zheng M, Yu J. A modified approach for drawing force estimation of bi-metallic composite pipe Forming. Compos. Part. ICMMBE. 2016;83:270-5.

[11] Yang XJ, Sun FH, Zhang ZM, et al. Optimization of drawing parameters for copper tubes with hollow sinking based on FEM simulation. J Nonferrous Metals. 2008;18(12):2245-52.

[12] Bi ZY, Wang C. Finite element simulation and experimental study of $\mathrm{L} 360 \mathrm{Q}$ /Incoloy 825 nickel base alloy hydraulic tube. J. Plast Eng. 2016;23(1):131-5.

[13] Olabi AG, Alaswad A. Experimental and finite element investigation of formability and failures in bi-layered tube hydroforming. Adv Eng Softw. 2011;42(10):815-20.

[14] Islam MD, Olabi AG, Hashmi MS. Feasibility of multi-layered tubular components forming by hydroforming and finite element simulation. J Mater Process Technol. 2006;174(1-3):394-8.

[15] Hossein SM. Seyedkashi, Panahizdeh R. Process Analysis of Two-layered Tube Hydroforming with Analytical and Experimental verification. J Mech Sci Technol. 2013;27(1):169-75.

[16] Kridli GT, Bao L, Mallick PK, Tian Y. Investigation of Thickness Variation and Corner Filling in Tube Hydroforming. J Mater Process Technol. 2003;133(3):287-96.

[17] Cao JB, Zhang ZS. Finite element analysis of underwater explosive forming of bimetal composite tube. Transactions of the China Welding Institution. 2018;39(2):61-5.

[18] Yu Y, Ma HH, Zhao K. Study on Explosive Welding of Al-Steel Coaxial Pipes Underwater. Cent Eur J Energ Mater. 2017;14(1):2516.

[19] Zamani E, Liaghat GH. Explosive welding of stainless steelcarbonsteel coaxial pipes. J Mater Sci. 2012;47(2):685-95.

[20] Sui GF, Li JS, Li HW, Sun F, Zhang T, Fu H. Investigation on the explosive welding mechanism of corrosion-resisting aluminium and stainless steel tubes through finite element simulation and experiments. Int J Miner Metall Mater. 2012;19(2):151-8.

[21] Miao GH, Ma HH, Shen ZW, Yu Y. Research on honeycomb structure explosives and double sided explosive cladding. Mater Des. 2014;63:538-43.

[22] Nechaykina T, Nikulin S, Rozhnov A, Molotnikov A, Zavodchikov $S$, Estrin Y. Proving the viability of manufacturing of multi-layer steel/vanadium alloy/steel composite tubes by numerical simulations and experiment. J Nucl Mater. 2018;503:178-90.

[23] Kazanowski P, Mario E, Wojciech Z. Bi-metal rod extrusionprocess and product optimization. Mater Sci Eng. 2004;369(12):170-80. 